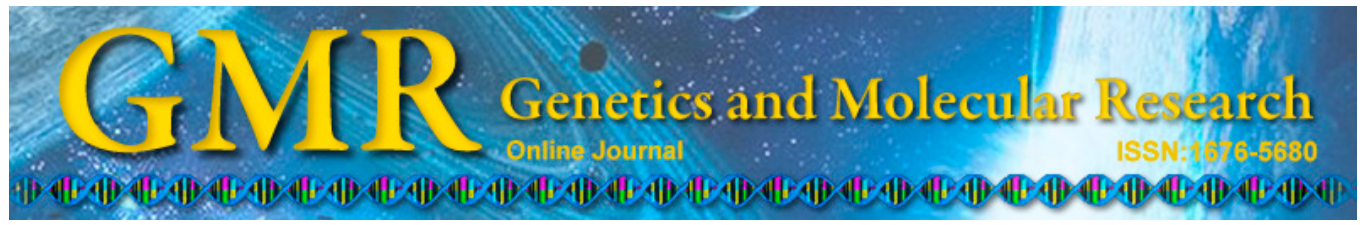

\title{
TCF7L2 gene polymorphisms and susceptibility to breast cancer: a meta-analysis
}

\author{
X.P. Lu ${ }^{1}$, G.N. Hu${ }^{2}$, J.Q. Du ${ }^{1}$ and H.Q. $\mathbf{L i}^{1}$ \\ ${ }^{1}$ Department of Gynecology and Obstetrics, \\ Dongyang People's Hospital, Dong Yang, China \\ ${ }^{2}$ Department of Breast Surgery, Dongyang People's Hospital, \\ Dong Yang, China \\ Corresponding author: X.P. Lu \\ E-mail: luxiping112@126.com
}

Genet. Mol. Res. 14 (1): 2860-2867 (2015)

Received March 17, 2014

Accepted August 13, 2014

Published March 31, 2015

DOI http://dx.doi.org/10.4238/2015.March.31.16

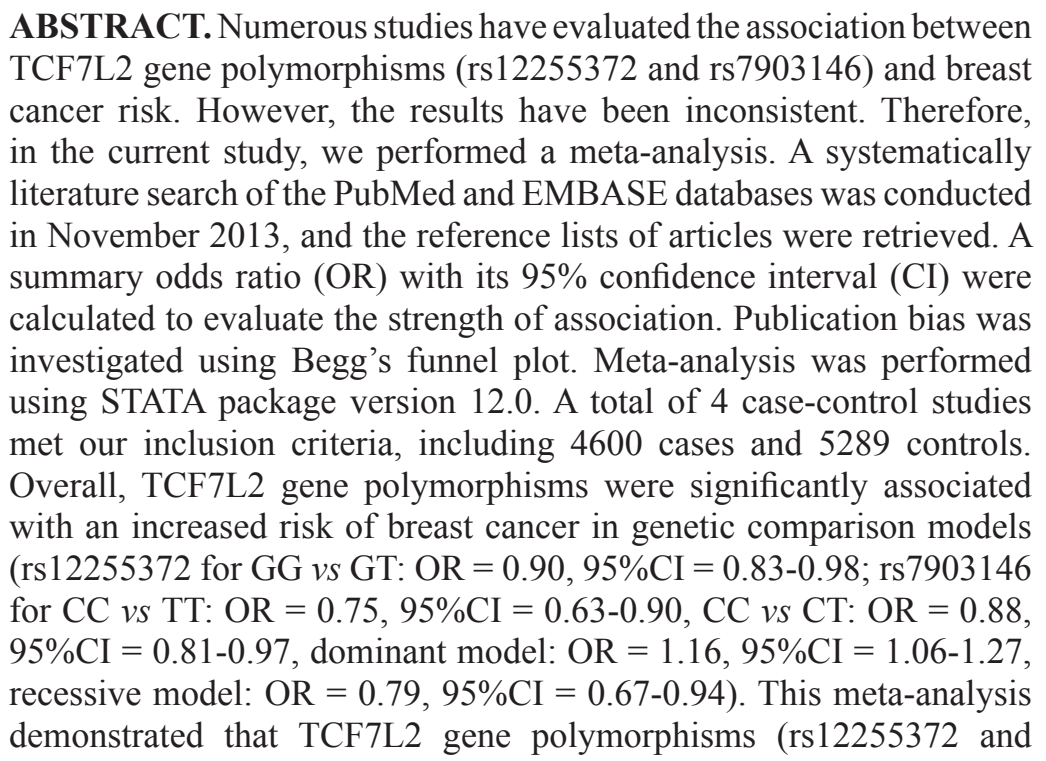


rs7903146) are associated with an increased susceptibility to breast cancer. However, further studies including large sample sizes are needed to validate this association.

Key words: Breast cancer; Metal analysis; TCF7L2 gene polymorphism

\section{INTRODUCTION}

Breast cancer is the most frequently diagnosed cancer and the leading cause of cancer death in females worldwide, accounting for $23 \%$ ( 1.38 million) of total new cancer cases and $14 \%$ of total cancer deaths in 2008. Approximately half of breast cancer cases and $60 \%$ of deaths are estimated to occur in economically developing countries (Jemal et al., 2011). Various factors may influence the development of breast cancer, including age at menarche, menopause, first birth age, and exogenous hormone use (Chen et al., 2013). In addition, epidemiological studies provide strong evidence that genetic factors are important in the pathogenesis of breast cancer, and approximately $27 \%$ of breast cancer cases are related to inherited susceptibility (Lichtenstein et al., 2000).

The transcription factor 7-like 2 (TCF7L2) gene is located on the long arm of chromosome 10q25.2, which was previously known as the TCF-4.TCF7L2 gene, and is part of the $\mathrm{Wnt} / \beta$-catenin signaling pathway, which plays a critical role in cell development and growth regulation (Ravindranath et al., 2008). The TCF7L2 protein is involved in blood glucose homeostasis, and its gene variants rs 12255372 and rs 7903146 have been reported to be associated with risk of type 2 diabetes (Bodhini et al., 2007). In addition, epidemiological studies demonstrated that TCF7L2 gene polymorphisms were associated with susceptibility to cancer (Sun et al., 2006).

Various studies have demonstrated that TCF7L2 rs12255372 and rs7903146 gene polymorphisms were associated with susceptibility to prostate cancer, colon cancer, colorectal cancer, lung cancer, and ovarian cancer (Agalliu et al., 2008; Folsom et al., 2008). However, little is known regarding the association between rs 12255372 or rs 7903146 variant and susceptibility to breast cancer. Over the past decade, several case-control studies have focused on the association between TCF7L2 gene polymorphisms and breast cancer risk. However, the results were inconsistent conflicting. Therefore, we performed a meta-analysis to clarify the association between the TCF7L2 gene rs12255372 and rs7903146 variants and breast cancer risk.

\section{MATERIAL AND METHODS}

\section{Selection of studies}

Systematic literature searches of the PubMed and EMBASE databases were conducted to identify previously published clinical studies. All search queries were updated through November 2013 using the following search strategy: ("breast cancer" or "TCF7L2") and ("rs12255372" or "rs 7903146" or "genotype" or "polymorphism"). In addition, the reference lists of the included articles and relevant meta-analyses were manually searched. Studies reported by the same authors were evaluated for possible overlapping participant groups. No language restrictions were applied. 


\section{Inclusion and exclusion criteria}

Studies were included in this meta-analysis if they met the following criteria: i) casecontrol studies that addressed breast cancer cases and healthy controls; ii) studies that evaluated the association between TCF7L2 gene polymorphisms (rs12255372 and rs7903146) and breast cancer risk, and iii) studies that included sufficient genotype data for extraction. Studies were excluded when: i) they were not case-control studies that evaluated the association between TCF7L2 gene polymorphisms (rs12255372 and rs7903146) and breast cancer risk; ii) case reports, letters, reviews, meta-analysis, and editorial articles; iii) studies based on incomplete data and those with no usable data reported; iv) duplicate data were contained, and v) healthy controls were not in Hardy-Weinberg equilibrium (HWE).

\section{Data extraction}

Information was extracted independently by 2 investigators according to the inclusion criteria described above (X.P. Lu and G.N. Hu). For each study, the following characteristics were collected: first author, year of publication, area, race, source of cases and controls, number of cases and controls, sample, polymorphisms, genotype frequency, and evidence of HWE in controls. For conflicting evaluations, an agreement was reached following discussion.

\section{Statistical analysis}

Meta-analysis was performed using the STATA package version 12.0 (Stata Corporation, College Station, TX, USA). To test for control population selective bias, a chi-square test was used to determine if the genotype distribution of the control subjects of each individual population was reported conformed to HWE $(\mathrm{P}<0.05$ was considered to be significant). The strength of the associations between TCF7L2 gene polymorphisms (rs12255372 and rs7903146) and susceptibility to breast cancer estimated based on the odds ratio (OR) and $95 \%$ confidence interval $(95 \% \mathrm{CI})$ under the co-dominant model (GG vs TT, GG vs GT or CC vs $\mathrm{TT}, \mathrm{CC}$ vs $\mathrm{CT})$, dominant model $(\mathrm{TT}+\mathrm{GT}$ vs $\mathrm{GG})$, and recessive model $(\mathrm{GG}+\mathrm{GT} v s \mathrm{TT})$ were calculated by the fixed-effect model or random-effect model. Between-study heterogeneities were estimated using the $\mathrm{I}^{2}$ test. $\mathrm{I}^{2}$ represents the variability attributed to heterogeneity rather than chance. $\mathrm{I}^{2}$ values of 25,50 , and $75 \%$ were defined as low, moderate, and high estimates, respectively. When a significant $\mathrm{I}^{2}>50 \%$ indicated heterogeneity across studies, the random-effect model was used for meta-analysis; otherwise, the fixed-effect model was used. Sensitivity analysis was performed by comparing random-effect model values to the fixed effect. Publication bias was investigated using Begg's funnel plot, and $\mathrm{P}<0.05$ was considered to be statistically significant publication bias.

\section{RESULTS}

\section{Study characteristics}

Based on the search criteria, 21 articles were identified. Of these, 13 studies were excluded after reading the title or abstract because these articles were irrelevant to our study. In addition, 2 duplicated publications and 1 review were excluded. One paper did not include a 
control group, which is why it was excluded. Therefore, only 4 studies addressing the association between TCF7L2 gene polymorphisms (rs12255372 and rs7903146) and breast cancer were analyzed in this meta-analysis (Burwinkel et al., 2006; Naidu et al., 2012; Connor et al., 2012; Alanazi et al., 2013). A flow chart summarizing the process of study inclusion/exclusion is depicted in Figure 1. The characteristics of each study are listed in Table 1, including 4600 cases and 5289 controls. All 4 eligible studies were hospital-based case-control studies. Of the 4 included studies, 3 used the restriction fragment length polymorphism method (Burwinkel et al., 2006; Naidu et al., 2012; Connor et al., 2012) and 1 used TaqMan Assays (Alanazi et al., 2013). All control samples were consistent with HWE $(\mathrm{P}>0.05)$.

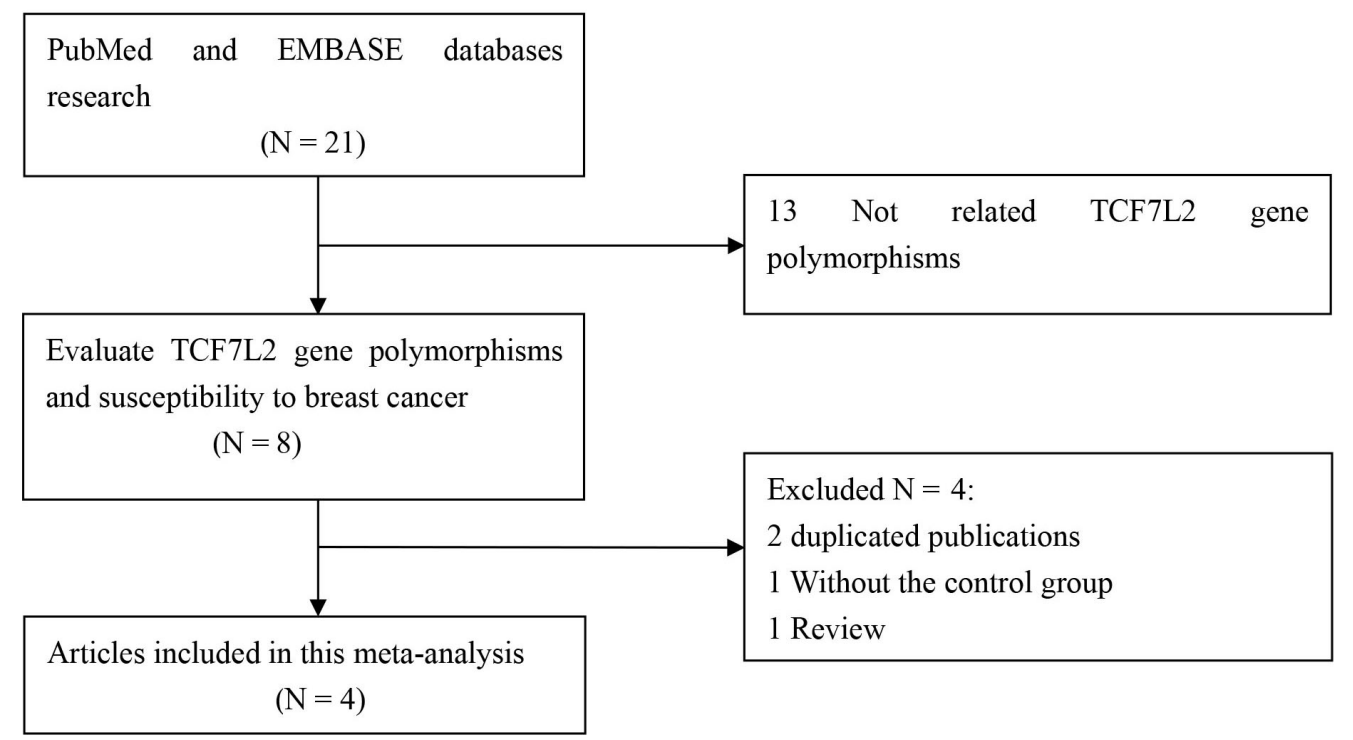

Figure 1. Flow chart of study searching and selection process.

\begin{tabular}{|c|c|c|c|c|c|c|c|c|c|c|c|}
\hline \multirow{2}{*}{$\frac{\text { Study included }}{\text { rs12255372 }}$} & \multirow[t]{2}{*}{ Year } & \multirow[t]{2}{*}{ Area } & \multirow[t]{2}{*}{ Race } & \multirow[t]{2}{*}{ Cases/Controls } & \multicolumn{3}{|c|}{ Genotypes for cases } & \multicolumn{3}{|c|}{ Genotypes for controls } & \multirow[t]{2}{*}{ HWE test } \\
\hline & & & & & GG & GT & TT & GG & GT & TT & \\
\hline Burwinkel & 2006 & Germany & Caucasians & $592 / 735$ & 297 & 244 & 51 & 408 & 276 & 51 & 0.64 \\
\hline Naidu & 2012 & Malaysia & Asians & $387 / 252$ & 186 & 167 & 34 & 141 & 95 & 16 & 0.99 \\
\hline Connor & 2012 & USA & Caucasians & $3522 / 4209$ & 2041 & 1252 & 229 & 2552 & 1431 & 226 & 0.17 \\
\hline Alanazi & 2013 & Saudi Arabia & Asians & 99/93 & 50 & 43 & 6 & 33 & 45 & 15 & 0.96 \\
\hline rs7903146 & & & & & $\mathrm{CC}$ & CT & TT & $\mathrm{CC}$ & CT & TT & \\
\hline Naidu & 2012 & Malaysia & Asians & $390 / 252$ & 187 & 163 & 40 & 140 & 93 & 19 & 0.52 \\
\hline Connor & 2012 & USA & Caucasians & $3523 / 4209$ & 1961 & 1304 & 258 & 2483 & 1476 & 250 & 0.12 \\
\hline
\end{tabular}

\section{Quantitative synthesis}

A summary of the meta-analysis findings regarding the association between TCF7L2 gene polymorphisms and breast cancer risk is shown in Table 2. For the rs12255372 poly- 
morphism, a total of 4600 cases and 5289 controls were identified. The meta-analysis results showed that the rs 12255372 polymorphism was related to an increased risk of breast cancer in the general population (Table 2 and Figure 2: for GG $v s$ GT: $\mathrm{OR}=0.90,95 \% \mathrm{CI}=0.83-0.98$ ). A total of 3913 cases and 4461 controls were identified for the rs 7903146 polymorphism. This meta-analysis suggested that the rs 7903146 polymorphism was significantly associated with an increased risk of breast cancer in genetic comparison models (Table 2 and Figure 3: for CC vs TT: $\mathrm{OR}=0.75,95 \% \mathrm{CI}=0.63-0.90 ; \mathrm{CC}$ vs $\mathrm{CT}: \mathrm{OR}=0.88,95 \% \mathrm{CI}=0.81-0.97$; dominant model: $\mathrm{OR}=1.16,95 \% \mathrm{CI}=1.06-1.27$; recessive model: $\mathrm{OR}=0.79,95 \% \mathrm{CI}=0.67-0.94$ ). Sensitivity analyses were conducted by altering the statistic models. No material alteration was detected, indicating that our results were statistically robust.

Table 2. Summary ORs and 95\%CI of TCF7L2 gene polymorphism and breast cancer risk.

\begin{tabular}{|c|c|c|c|c|c|c|c|c|c|c|}
\hline \multirow[t]{2}{*}{ Subgroup } & \multirow[t]{2}{*}{ Genetic model } & \multicolumn{2}{|c|}{ Sample size } & \multirow[t]{2}{*}{ Type of model } & \multicolumn{2}{|c|}{ Test of heterogeneity } & \multicolumn{2}{|c|}{ Test of association } & \multicolumn{2}{|c|}{ Test of publication bias } \\
\hline & & Case & Control & & $\mathrm{I}^{2}$ & $\mathrm{P}$ & OR & $95 \% \mathrm{CI}$ & $\mathrm{z}$ & $\mathrm{P}$ \\
\hline \multirow[t]{4}{*}{ rs12255372 } & GG vs TT & \multirow[t]{4}{*}{4600} & \multirow[t]{4}{*}{5289} & Random & $68.0 \%$ & 0.03 & 0.88 & $0.58-1.34$ & 0.00 & 1.00 \\
\hline & GG $v s \mathrm{GT}$ & & & Fixed & $42.0 \%$ & 0.16 & 0.90 & $0.83-0.98$ & 0.00 & 1.00 \\
\hline & Dominant model & & & Random & $64.5 \%$ & 0.04 & 1.12 & $0.91-1.37$ & 0.00 & 1.00 \\
\hline & Recessive model & & & Random & $55.4 \%$ & 0.08 & 0.89 & $0.63-1.25$ & 0.00 & 1.00 \\
\hline \multirow[t]{4}{*}{ rs7903146 } & $\mathrm{CC} v s \mathrm{TT}$ & \multirow[t]{4}{*}{3913} & \multirow[t]{4}{*}{4461} & Fixed & $0.0 \%$ & 0.55 & 0.75 & $0.63-0.90$ & 0.00 & 1.00 \\
\hline & $\mathrm{CC} v s \mathrm{CT}$ & & & Fixed & $0.0 \%$ & 0.37 & 0.88 & $0.81-0.97$ & 0.00 & 1.00 \\
\hline & Dominant model & & & Fixed & $0.4 \%$ & 0.32 & 1.16 & $1.06-1.27$ & 0.00 & 1.00 \\
\hline & Recessive model & & & Fixed & $0.0 \%$ & 0.71 & 0.79 & $0.67-0.94$ & 0.00 & 1.00 \\
\hline
\end{tabular}

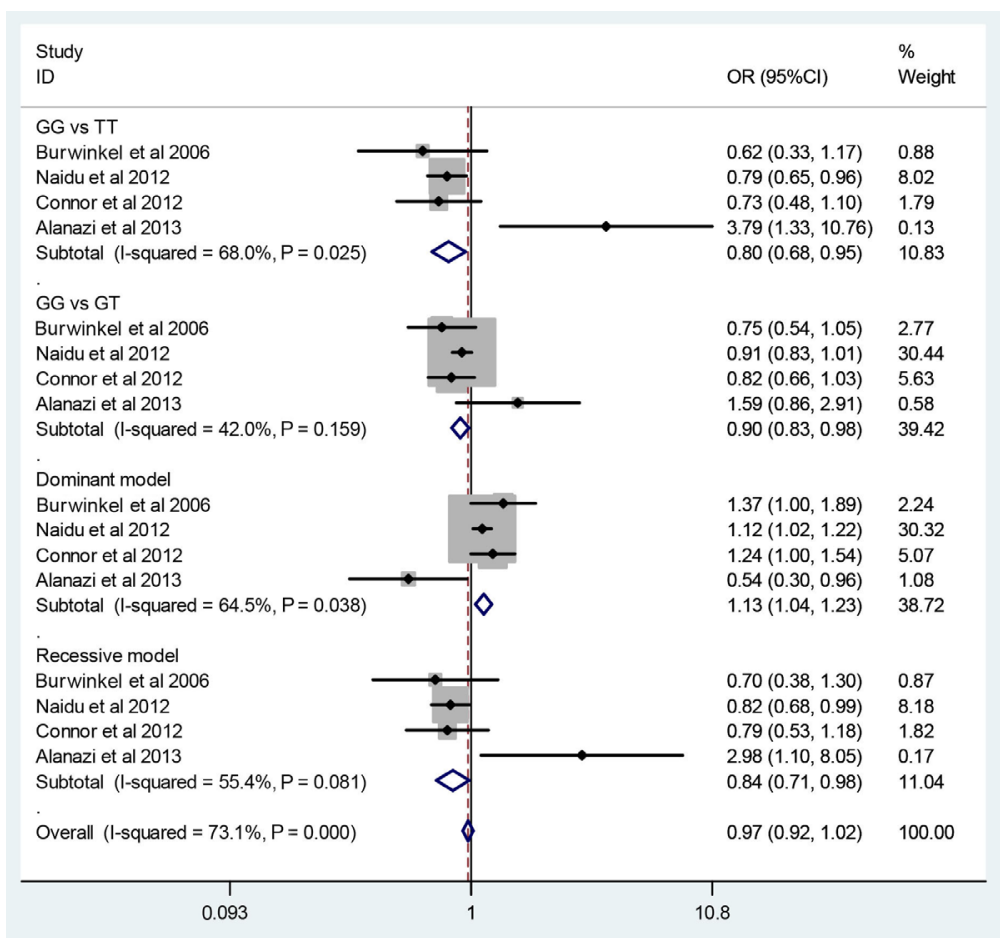

Figure 2. Association between the rs12255372 polymorphism and breast cancer risk. 


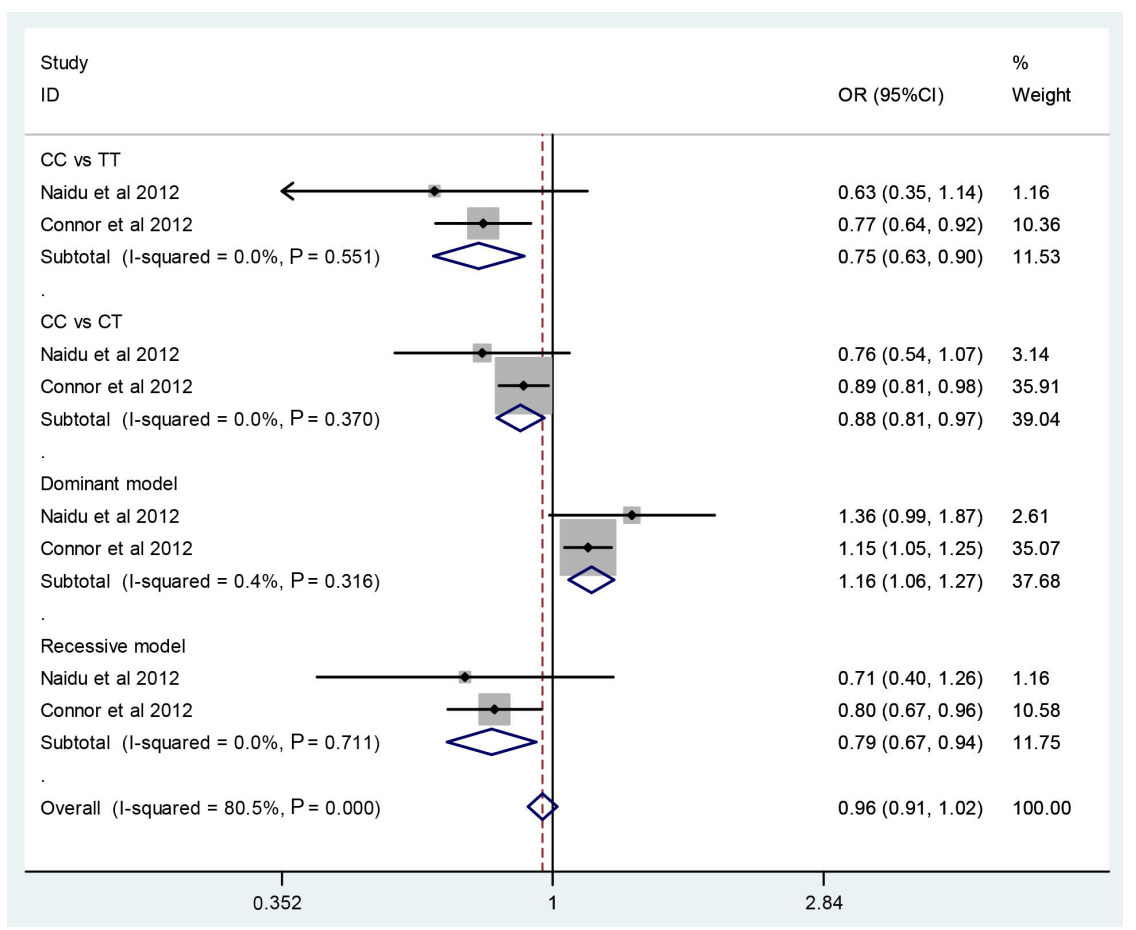

Figure 3. Association between the rs 7903146 polymorphism and breast cancer risk.

\section{Publication bias}

Publication bias of the literature was assessed by Begg's funnel plot (Table 2). The funnel plot was used to measure the asymmetry of the funnel plot. The results of the Begg's funnel plot are shown in Table 2. Results showed that there was no publication bias (all $\mathrm{P}>0.05$ ).

\section{DISCUSSION}

TCF7L2 gene variants have been reported to be associated with risk of type 2 diabetes in different populations (Grant et al., 2006). In addition, TCF7L2 may affect cancer independently of diabetes, as the TCF7L2 gene product is involved the Wnt/-catenin signaling pathway. TCF7L2 forms an active nuclear complex with $\beta$-catenin that binds and induces the expression of target genes involved in cellular proliferation, evasion of apoptosis, tissue invasion, and metastasis (Reya and Clevers, 2005). Few epidemiological studies have examined the association between TCF7L2 gene polymorphisms and breast cancer risk with contradictory results. Naidu et al. (2012) reported that the rs7903146 (T) variant may elevate the risk of breast cancer, and thus is a potential candidate for breast cancer susceptibility, and rs 12255372 was not associated with risk of breast cancer. Burwinkel et al. (2006) examined the association between rs12255372 and familial breast cancer risk and reported that the $\mathrm{T}$ allele was significantly associated with break cancer risk. In contrast, Goode et al. (2009) found no overall association. Meta-analysis is a method that examines related studies, published or 
unpublished, and applying statistical methods to compare data and reach quantitative conclusions. In this study, we performed meta-analysis to investigate whether TCF7L2 variants are associated with breast cancer risk.

This is the first meta-analysis examining the association between TCF7L2 gene polymorphisms (rs12255372 and rs7903146) and breast cancer risk. Only 4 case-control studies were included in this analysis, and included 4600 patients and 5289 healthy controls. We found that the rs 12255372 polymorphism was significantly associated with an increased risk of breast cancer (GG vs GT; OR $=0.90,95 \% \mathrm{CI}=0.83-0.98)$. For rs7903146, the meta-analysis indicated a significant association between the rs 7903146 polymorphism and breast cancer susceptibility among the overall population (CC vs TT: $\mathrm{OR}=0.75,95 \% \mathrm{CI}=0.63-0.90 ; \mathrm{CC} v s \mathrm{CT}$ : $\mathrm{OR}=0.88$, $95 \% \mathrm{CI}=0.81-0.97$; dominant model: $\mathrm{OR}=1.16,95 \% \mathrm{CI}=1.06-1.27$; recessive model: $\mathrm{OR}=$ $0.79,95 \% \mathrm{CI}=0.67-0.94)$. We observed no publication bias in this meta-analysis regarding the association between TCF7L2 gene polymorphisms and susceptibility to breast cancer.

The mechanism of how TCF7L2 gene polymorphisms are related to breast cancer risk remains unclear. The TCF7L2 gene product is involved the Wnt/ $\beta$-catenin signaling pathway, and deregulation of the Wnt pathway is involved in the mechanisms of carcinogenesis (Reya and Clevers, 2005). In addition, the potential function of TCF7L2 gene polymorphisms may be affected via gene-gene interactions, and the TCF7L2 rs7904519 (in intron 4 of TCF7L2), rs12255372, and rs7903146 alleles have been found to be in linkage disequilibrium. These haplotypes were associated with increased risk of breast cancer (Michailidou et al., 2013). Further studies of gene-gene interactions should be conducted to examine breast cancer risk.

There were some limitations to our meta-analysis. First, the random-effect model was used to calculate ORs, which may have affected the precision of the results. Second, there was not sufficient individual information regarding genotypes of both the TCF7L2 rs 12255372 and rs7903146 polymorphisms, and we could not perform combined analysis of linkage disequilibrium. Therefore, more studies including a larger sample size and more detail information are needed. Finally, the genotype information stratified for the main confounding variables was not available in the original papers, such as age, gender, ethnicity, and exposures. These confounding factors may cause serious confounding bias.

In summary, this meta-analysis evaluated the effect of TCF7L2 gene polymorphisms on the risk of breast cancer. We found that TCF7L2 gene polymorphisms are associated with an increased susceptibility to breast cancer. Additional studies should be conducted to verify our results.

\section{Conflicts of interest}

The authors declare no conflict of interest.

\section{REFERENCES}

Agalliu I, Suuriniemi M, Prokunina-Olsson L, Johanneson B, et al. (2008). Evaluation of a variant in the transcription factor 7-like 2 (TCF7L2) gene and prostate cancer risk in a population-based study. Prostate 68: 740-747.

Alanazi MS, Parine NR, Shaik JP, Alabdulkarim HA, et al. (2013). Association of single nucleotide polymorphisms in Wnt signaling pathway genes with breast cancer in Saudi patients. PLoS One 8: e59555.

Bodhini D, Radha V, Dhar M, Narayani N, et al. (2007). The rs12255372(G/T) and rs7903146(C/T) polymorphisms of the TCF7L2 gene are associated with type 2 diabetes mellitus in Asian Indians. Metabolism 56: 1174-1178.

Burwinkel B, Shanmugam KS, Hemminki K, Meindl A, et al. (2006). Transcription factor 7-like 2 (TCF7L2) variant is associated with familial breast cancer risk: a case-control study. BMC Cancer 17: 268. 
Chen Q, Shi R, Liu W and Jiang D (2013). Assessing interactions between the association of common genetic variant at $1 \mathrm{p} 11$ (rs11249433) and hormone receptor status with breast cancer risk. PLoS One 8: e72487.

Connor AE, Baumgartner RN, Baumgartner KB, Kerber RA, et al. (2012). Associations between TCF7L2 polymorphisms and risk of breast cancer among Hispanic and non-Hispanic white women: the Breast Cancer Health Disparities Study. Breast Cancer Res. Treat. 136: 593-602.

Folsom AR, Pankow JS, Peacock JM, Bielinski SJ, et al. (2008). Variation in TCF7L2 and increased risk of colon cancer: the Atherosclerosis Risk in Communities (ARIC) Study. Diabetes Care 31: 905-909.

Goode EL, Szabo C, Prokunina-Olsson L, Vierkant RA, et al. (2009). No association between a candidate TCF7L2 variant and risk of breast or ovarian cancer. BMC Cancer 9: 312.

Grant SF, Thorleifsson G, Reynisdottir I, Benediktsson R, et al. (2006). Variant of transcription factor 7-like 2 (TCF7L2) gene confers risk of type diabetes. Nat. Genet. 38: 320-323.

Jemal A, Bray F, Center MM, Ferlay J, et al. (2011). Global cancer statistics. CA Cancer J. Clin. 61: 69-90.

Lichtenstein P, Holm NV, Verkasalo PK, Iliadou A, et al. (2000). Environmental and heritable factors in the causation of cancer-analyses of cohorts of twins from Sweden, Denmark, and Finland. N. Engl. J. Med. 343: 78-85.

Michailidou K, Hall P, Gonzalez-Neira A, Ghoussaini M, et al. (2013). Large-scale genotyping identifies 41 new loci associated with breast cancer risk. Nat. Genet. 45: 353-361, 361e1-2.

Naidu R, Yip CH and Taib NA (2012). Genetic variations in transcription factor 7-like 2 (TCF7L2) gene: association of TCF7L2 rs12255372(G/T) or rs7903146(C/T) with breast cancer risk and clinico-pathological parameters. Med. Oncol. 29: 411-417.

Ravindranath A, O'Connell A, Johnston PG and El-Tanani MK (2008). The role of LEF/TCF factors in neoplastic transformation. Curr. Mol. Med. 8: 38-50.

Reya T and Clevers H (2005). Wnt signalling in stem cells and cancer. Nature 434: 843-850.

Sun P, Xiong H, Kim TH, Ren B, et al. (2006). Positive inter-regulation between beta-catenin/T cell factor-4 signaling and endothelin-1 signaling potentiates proliferation and survival of prostate cancer cells. Mol. Pharmacol. 69: 520-531. 